\section{Digestion}

Beglinger, C. 1

Biedermann, L. 6, 36, 45

Burri, E. 1

Chevaux, J.-B. 16

Frei, P. 6, 11, 36

Girardin, M. 6

Kiss, L.S. 28

Aminosalicylates 36

Breastfeeding 45

Calprotectin 1

C-reactive protein 1

Crohn's disease 6, 11, 16, 23

Crohn's disease 28

Endoscopic indices 16

Enema 36

Extraintestinal manifestations 28
Lakatos, L. 28

Lakatos, P.L. 11, 16, 28

Lehmann, F.S. 1

Manser, C.N. 6, 36

Manz, M. 6, 11, 36

Mottet, C. 6, 23

Peyrin-Biroulet, L. 16, 23, 28

Rogler, G. IV, 6, 11, 16, 36, 45
Safroneeva, E. 6, 11, 23

Schoepfer, A.M. 6, 11, 16, 23, 28

Seibold, F. 45

Seirafi, M. 45

Vavricka, S.R. IV, 11, 16, 23, 28, 36, 45

Wanner, R. 6, 11

Wilk, M. 36

\title{
Subject Index Vol. 86, Suppl. 1, 2012
}

First-line treatment 6

Foam 36

Inflammatory bowel disease $1,6,28$

Medical therapy benefits 45

Monitoring of treatment response 1

Mucosal healing 16

Perianal fistulas 23

Pregnancy 45
Steroid-resistant inflammatory bowel disease 11

Steroids 6

Stricture 23

Topical therapy 36

Ulcerative colitis $6,11,16,28,36$ 